\title{
Rare large colloid cyst obstructing the posterior third ventricle: illustrative case
}

\author{
Jakob V. E. Gerstl, BSc, ${ }^{1}$ Kristian Aquilina, MD, FRCS(SN), ${ }^{2}$ and Jeffrey E. Florman, $\mathrm{MD}^{3,4}$ \\ ${ }^{1}$ University College London Medical School, London, United Kingdom; ${ }^{2}$ Department of Neurosurgery, Great Ormond Street Hospital for Children, London, United Kingdom; \\ ${ }^{3}$ Neuroscience Institute, Maine Medical Center, Portland, Maine; and ${ }^{4}$ Department of Neurosurgery, Tufts University Medical Center, Boston, Massachusetts
}

\begin{abstract}
BACKGROUND Colloid cysts of the posterior third ventricle are exceedingly rare. This location is a high-risk zone for colloid cysts because of potential obstruction of the cerebral aqueduct.

OBSERVATIONS The authors report a case of a 57-year-old man who presented with a 6-month history of progressive headache, short-term memory loss, visual blurring, and an episode of double vision. Magnetic resonance imaging (MRI) revealed a colloid cyst, $22 \mathrm{~mm}$ in diameter, attached to the roof of the posterior third ventricle. The posterior third ventricle was obstructed, but both foramina of Monro were patent. The entirety of the cyst was resected via a right frontal parasagittal, interhemispheric, transventricular approach through the foramen of Monro. It was not contained within the velum interpositum. The patient did not experience any postoperative deficits.

LESSONS This case supports the theoretical evidence that colloid cysts in the posterior zone of the third ventricle pose a risk for obstructive hydrocephalus. This report of a large cyst in a rare location describes a unique lesion and provides the first published MRI description.
\end{abstract}

https://thejns.org/doi/abs/10.3171/CASE2121

KEYWORDS colloid cyst; posterior third ventricle; hydrocephalus; cerebral aqueduct

Colloid cysts are benign lesions that account for approximately $1 \%$ of all intracranial neoplasms and typically present in patients between 20 and 40 years of age. ${ }^{1}$ Many are asymptomatic and discovered incidentally. Most commonly, colloid cysts grow in the anterior roof of the third ventricle and can obstruct the foramen of Monro. The subsequent hydrocephalus typically presents with symptoms of ataxia, headache, and memory impairment, which are most commonly slowly progressive. Cases of rapid deterioration occur in $3 \%-35 \%$ of patients but usually have a background of chronic symptoms. ${ }^{2,3}$

Risk factors for the development of symptoms and hydrocephalus include age $<65$ years, axial cyst diameter $\geq 7 \mathrm{~mm}$, fluid-attenuated inversion recovery (FLAIR) hyperintensity in the cyst, and location of the cyst within the third ventricle. ${ }^{4}$ Beaumont et al. ${ }^{4}$ divided the third ventricle into zones, each considered high or low risk. Classically, colloid cysts found at zone I, anterior to the anterior aspect of the massa intermedia, are considered high risk as they can obstruct the foramen of Monro. Zone II, stretching from the posterior end of zone I to the rostral apex of the midbrain tegmentum at the inlet of the cerebral aqueduct, is considered a low-risk zone, and Beaumont et al. ${ }^{4}$ report no cases of cysts causing obstructive hydrocephalus in the region. Last, zone III, the posterior zone, while considered high risk because of the potential to obstruct the cerebral aqueduct, is an exceedingly rare location for a colloid cyst. The authors reported only 1 of their 163 cases in this region, and they believed that it represented a dislodged cyst from the anterior third ventricle.

The literature presents either very old reports of cysts in the posterior third ventricle lacking magnetic resonance imaging (MRI) ${ }^{5,6}$ or reports of colloid cysts from that region growing superiorly, such as if arising within the velum interpositum ${ }^{7,8}$ and therefore not obstructing the third ventricle or cerebral aqueduct. Our report describes a unique colloid cyst filling and obstructing the posterior third ventricle without obstructing either foramen of Monro.

\section{Illustrative Case \\ Presentation}

A 57-year-old man with a recent history of Lyme disease presented with a 6-month history of short-term memory impairment, worsening headache, progressive visual blurring, and an episode of double vision.

ABBREVIATIONS FLAIR = fluid-attenuated inversion recovery; MRI = magnetic resonance imaging.

INCLUDE WHEN CITING Published online April 12, 2021; DOI: 10.3171/CASE2121.

SUBMITTED January 21, 2021. ACCEPTED January 26, 2021.

(c) 2021 The authors, CC BY-NC-ND 4.0 (http://creativecommons.org/licenses/by-nc-nd/4.0/). 


\section{Examination}

On examination, the patient was awake and alert but struggled to recall the current year. He had an otherwise nonfocal neurological examination. Noncontrast MRI of the brain revealed a $22-\mathrm{mm}$, relatively round intraventricular mass in the posterior third ventricle (zone III). There was no obstruction of the foramen of Monro on either side and no direct obstruction of the cerebral aqueduct. However, the mass filled the entirety of the posterior ventricle, and there was an obstructive pattern of hydrocephalus with marked dilation of the lateral ventricles and anterior third ventricle but a small fourth ventricle (Fig. 1). There was some minor "capping" of the frontal horns of the lateral ventricles on the FLAIR sequence. This mass was hypointense on a T2-weighted image and hyperintense on a T1-weighted image.

\section{Operation}

A right, frontal, parasagittal, interhemispheric, transventricular approach through the foramen of Monro was used. The dilation of the foramen of Monro allowed access for decompression of the cyst contents and reduction of the capsule into view for resection. A gross-total excision was achieved with cautery of a very small attachment posterior to the foramen of Monro (Fig. 2).

\section{Histopathological Evaluation}

The finding of histopathological evaluation was consistent with a colloid cyst.

\section{Postoperative Course}

The patient recovered well from surgery with improved symptoms and no frank memory impairment.

\section{Discussion}

\section{Observations}

Colloid cysts arise from the neuroepithelium and may therefore develop at any point of the central nervous system where neuroepithelium is present. ${ }^{9}$ Albeit rare, colloid cysts have also been described in locations outside the third ventricle, including the pituitary gland ${ }^{10}$ and the fourth ventricle. ${ }^{6,9}$ The vast majority present in the third ventricle intimate to the foramen of Monro, with symptomatic posterior third ventricle cysts being particularly rare. While a case
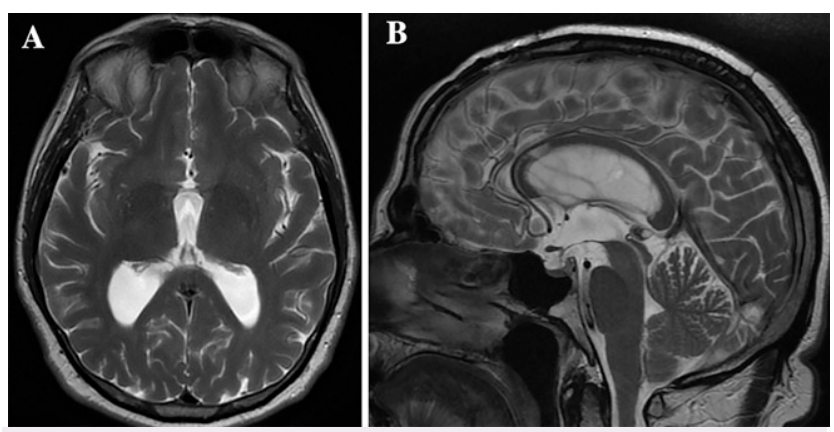

FIG. 2. Postoperative MRI following a parasagittal interhemispheric approach. A: Axial T2-weighted MRI scan. B: Sagittal T2-weighted MRI scan.

of a zone I colloid cyst that "metastasized" to obstruct in zone III following a fall has been reported, ${ }^{4}$ a case of a cyst similar to our patient's arising in zone III and obstructing the posterior third ventricle has not been visualized with MRI.

Furthermore, while comparatively small cysts arising close to the foramen of Monro may be symptomatic, as even a small mass can cause obstruction, ${ }^{11}$ a colloid cyst arising in the roof of the posterior ventricle requires significant size to be of clinical consequence.

In addition to origin and size, the direction of cyst growth is relevant and often depends on the anatomical origin of the cyst as it relates to variance in the point of forniceal column divergence from the body of the fornix. ${ }^{12}$ Normally, this point of divergence is relatively anterior, and a classic cyst arising anteriorly in the roof of the third ventricle therefore grows inferiorly to obstruct the foramen of Monro. Exceptions do exist, such as an anterior cyst in a retroforaminal position dissecting through the raphe fornix, allowing it to expand superoposteriorly into the cavum of the septum pellucidum. ${ }^{13}$ However, more commonly, a cyst arising relatively posteriorly in an anteriorly diverging fornix finds a low-resistance path to grow superoposteriorly. ${ }^{12}$ By the same principle, in a posteriorly diverging fornix, an anteriorly arising colloid cyst can grow to a relatively large size by growing superoanteriorly. A cyst growing in an inferior direction toward the
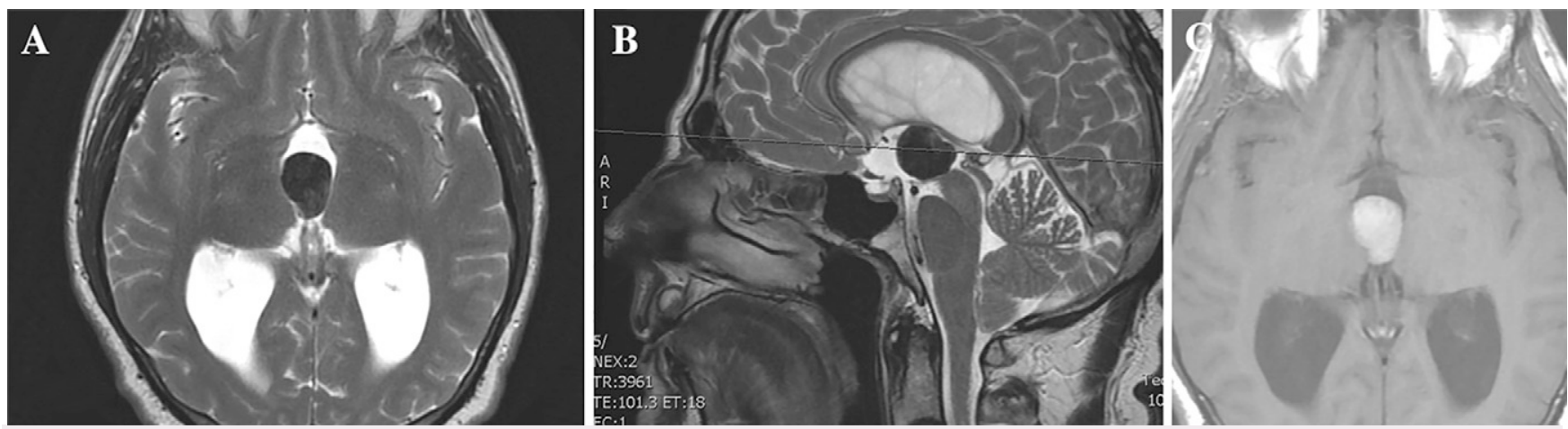

FIG. 1. Preoperative MRI. A: Axial T2-weighted image. B: Sagittal T2-weighted image. C: Axial T1-weighted image. The colloid cyst measured $22 \mathrm{~mm}$ in diameter, growing from the superior roof of the third ventricle and completely obstructing the posterior third ventricle but neither foramen of Monro. 
aqueduct, arising posteriorly in a posteriorly diverging fornix, is the event described in this article.

Conservative care, cerebrospinal fluid diversion, open surgical approaches, and neuroendoscopy have been applied to the management of colloid cysts. ${ }^{14}$ The interhemispheric transforaminal approach is known to be advantageous in large colloid cysts ${ }^{15}$ and successfully allowed the gross-total resection of this large cyst despite the posterior location.

\section{Lessons}

This case illustrates a large zone III colloid cyst obstructing the posterior third ventricle and successfully managed by interhemispheric transforaminal surgery. Posterior cysts are extremely rare, and their presentation is likely dependent on patient anatomy, such as forniceal variations and large size. Excellent outcomes with surgery can be achieved.

\section{References}

1. Hernesniemi J, Leivo S. Management outcome in third ventricular colloid cysts in a defined population: a series of 40 patients treated mainly by transcallosal microsurgery. Surg Neurol. 1996;45(1):2-14.

2. de Witt Hamer PC, Verstegen MJT, De Haan RJ, et al. High risk of acute deterioration in patients harboring symptomatic colloid cysts of the third ventricle. J Neurosurg. 2002;96(6):1041-1045.

3. Büttner A, Winkler PA, Eisenmenger W, Weis S. Colloid cysts of the third ventricle with fatal outcome: a report of two cases and review of the literature. Int J Legal Med. 1997;110(5):260-266.

4. Beaumont TL, Limbrick DD Jr, Rich KM, et al. Natural history of colloid cysts of the third ventricle. J Neurosurg. 2016;125(6):14201430.

5. Case records of the Massachusetts General Hospital. Case 32152. N Engl J Med. 1946;234:511-514. doi: 10.1056/ NEJM194604112341506

6. Palacios E, Azar-Kia B, Shannon M, Messina AV. Neuroepithelial (colloid) cysts. Pathogenesis and unusual features. AJR Am J Roentgenol. 1976;126(1):56-62.

7. Morris TC, Santoreneos S. Colloid cyst of velum interpositum: a rare finding. J Neurosurg Pediatr. 2012;9(2):206-208.

8. Al-Sharydah AM, Al-Suhibani SS, Al-Abdulwahhab AH, et al. A unique finding of cavum velum interpositum colloid-like cyst and literature review of a commonplace lesion in an uncommon place. Int J Gen Med. 2018;11:301-305.

9. Hasegawa M, Nouri M, Nagahisa S, et al. Neuroepithelial cyst of the fourth ventricle. Childs Nerv Syst. 2015;31(1):155-159.

10. Bladowska J, Bednarek-Tupikowska G, Biel A, Sąsiadek M. Colloid cyst of the pituitary gland: case report and literature review. Pol J Radiol. 2010;75(2):88-93.

11. Jeffree RL, Besser M. Colloid cyst of the third ventricle: a clinical review of 39 cases. J Clin Neurosci. 2001;8(4):328-331.

12. Azab WA, Salaheddin W, Alsheikh TM, et al. Colloid cysts posterior and anterior to the foramen of Monro: anatomical features and implications for endoscopic excision. Surg Neurol Int. 2014;5:124.

13. Vialogo JG. Endoscopic transepto-interforniceal approach to colloid cysts: case report. Article in Portuguese. Arq Neuropsiquiatr. 2000; 58(3B):939-946.

14. Yadav YR, Yadav N, Parihar V, et al. Management of colloid cyst of third ventricle. Turk Neurosurg. 2015;25(3):362-371.

15. Kondziolka D, Lunsford LD. Microsurgical resection of colloid cysts using a stereotactic transventricular approach. Surg Neurol. 1996; 46(5):485-492.

\section{Disclosures}

The authors report no conflict of interest concerning the materials or methods used in this study or the findings specified in this paper.

\section{Author Contributions}

Conception and design: Florman, Gerstl. Acquisition of data: Florman. Analysis and interpretation of data: Florman, Gerstl. Drafting the article: Florman, Gerstl. Critically revising the article: all authors. Reviewed submitted version of manuscript: all authors. Approved the final version of the manuscript on behalf of all authors: Florman. Administrative/ technical/material support: Florman. Study supervision: Florman.

\section{Correspondence}

Jeffrey E. Florman: Maine Medical Center, Portland, ME. flormj@mmc. org. 